\title{
III. On the diurnal variations of magnetic elements, as depending on the method of tabulation
}

\section{William Ellis F.R.A.S.}

To cite this article: William Ellis F.R.A.S. (1891) III. On the diurnal variations of magnetic elements, as depending on the method of tabulation, Philosophical Magazine Series 5, 31:188, 36-41, DOI: $10.1080 / 14786449108620067$

To link to this article: http://dx.doi.org/10.1080/14786449108620067

曲 Published online: 08 May 2009.

Submit your article to this journal $[\pi$

Џll Article views: 2

Q View related articles 
III. On the Diurnal Variations of Magnetic Elements, as depending on the Method of Tabulation. By WiLliam ElLIs, F.R.A.S., of the Royal Observatory, Greenwich*.

TTHE interesting paper of Messrs. Robson and Smith, "On 1 the Diurnal Variation of the Magnet at Kew," which appears in the August number of the Philosophical Magazine (page 140), includes a comparison between the diurnal inequality of the declination-magnet as determined at the Greenwich and Kew Observatories in the years 1870, 1871, $1872,1883,1886$, and 1887 .

The Kew results for the years 1883,1886 , and 1887 were determined by the authors of the paper by Wild's method, the hourly ordinates for about five quiet days in each month having been measured. Those for the years 1870,1871 , and 1872 had been previously determined by Mr. Whipple, Superintendent of the Kew Observatory, and by him communicated to the 1886 Report of the British Association Committee on Comparing and Reducing Magnetic Observations; and were, as Mr. Whipple kindly informs me, calculated from the records of four selected quiet days in each month of the three years. The results for the whole six years are thus in every respect comparative.

The Greenwich results with which those for Kew were compared were deduced, not from selected days, but from the records for all days excepting those, comparatively few in number, on which either the magnet was excessively disturbed, or the record from some accidental cause was wanting. Whenever results for all days are hereafter mentioned, it will be understood to be with this limitation. For the days thus employed a pencil line was drawn by hand through each photographic trace so as to represent the general form of the curve, neglecting its petty irregularities, but giving consideration to deviations of marked character. The hourly ordinates were measured from such pencilled line, and it is on the measures so made that the diurnal inequalities contained in the Greenwich volumes, and employed by Messrs. Robson and Smith, depend.

Comparing together the Greenwich and Kew results for declination, found in the way described, Messrs. Robson and

* Communicated by the Author. 
Smith showed that there existed a periodical difference in the diurnal inequality, similar in character, and generally also in magnitude, in each of the six years treated. Mr. Whipple, in the British Association Report before alluded to, had previously pointed out the existence of this periodical difference in the three years with which he dealt, and suggested that it might be in some measure due to instrumental causes, and in some degree also to difference of geographical position, which considerations would apply equally to the comparison of the years 1883,1886 , and 1887 ; but how far such causes mav have acted, it was impossible from a comparison of this kind to determine.

Circumstances have now, however, arisen which enable us to make a direct comparison of the two methods of tabulation.

In compliance with a request made by the Sub-Committee of the Kew Committee of the Royal Society, the Astronomer Royal has arranged to select, yearly, five quiet days in each month, to be generally adopted for the discussion and comparison of the dinrnal inequalities of magnetism at the various British magnetic observatories, in consequence of which diurnal inequalities will now be determined at Greenwich for these selected quiet days, as well as for all days in the manner which has been so long employed. The work at Greenwich for the first year under this arrangement, that of 1889 , having been lately completed, opportunity is now given for making a direct comparison of methods, a comparison in which the question of difference of instruments or of geographical position in no way enters. Viewing the interest attaching to this matter, the Astronomer Royal has kindly given me permission to communicate to the Philosophical Magazine the results arrived at for the year mentioned.

The present comparison has been made not only for declination, but also for the horizontal and vertical forces, and the results are contained in the accompanying Table. The diurnal inequalities on the two systems, and their differences, are given, in the case of declination in minutes of arc, and for the horizontal and vertical forces in parts of these forces. But in order to make the comparison between the several elements more complete, the differences have been further converted into metric measure, those of declination being expressed as westerly force, the unit employed in the Table being 00001 of the metric unit. The metric differences are also exhibited in the form of curves, for comparison with the curves for declination given by Messrs. Robson and 
Smith *. The Greenwich declination-curve is less bold than that of Messrs. Robson and Smith, but in other respects shows great similarity, both in form and in the position of the nodal points. The deficiency in boldness may be a peculiarity of the year under discussion, the epoch being one of minimum magnetic activity.

The periodical difference shown by Messrs. Robson and Smith to exist between the Greenwich and Kew diurnal inequality of declination, as deduced at Greenwich from all days and at Kew from quiet days, thus appears to depend on difference in the charaeier of the records employed; since the discussion of Greenwich records alone, on the two systems mentioned, leads to the same conclusion, not only as regards declination, but also for the horizontal and vertical forces. A difference of the same general character is shown in each element in all months of the year: these particulars could not well be given her', but it has been thought interesting to add in the Table the summer and winter effects, taking summer as including the months from April to September, and winter the remaining months of the year.

'The records used in the formation of the Greenwich all days' results contain many irregularities which are smoothed in the way before mentioned. The quiet days, in 1889 , contain practically no irregularities. It might thus be conjectured that something may be due to systematic bias in the performance of the smoothing operation; but it could, if nece-sary, be shown that no influence of this kind would produce differences so dissimilar in eharacter for the different elements; besides which irregularities in the vertical-force record are so infirequent, and in the year treated so few and trifling, that practically no smoothing had to be done; but yet the curve for vertical force, as maty be seen, is quite as pronounced as those for either of the other elements, and indeed forms a very much larger proportion of the whole diurnal inequality for vertical force (see the Table) than is the case for either of the other elements.

The difference between the two methods of deternining diurnal inequality thus appears to arise from a physical canse, the form of the diurnal inequality-curve found by including all days differing in a systematic way from that given by using selected quiet days, in the manner shown in the diagrans. The nodal points in the horizontal-force and vertical-force

* The vertical divisions on the diagram correspond eaciz to 03.32 .5 metric of :0\%00\%5 C.G.S. measure, equivalent on the declin titio:-curve to $0^{*} .47$ in are, whilst those on Messrs. R,bson and Smith's diagrit.n repres tnt each $0^{\prime} 50$. 


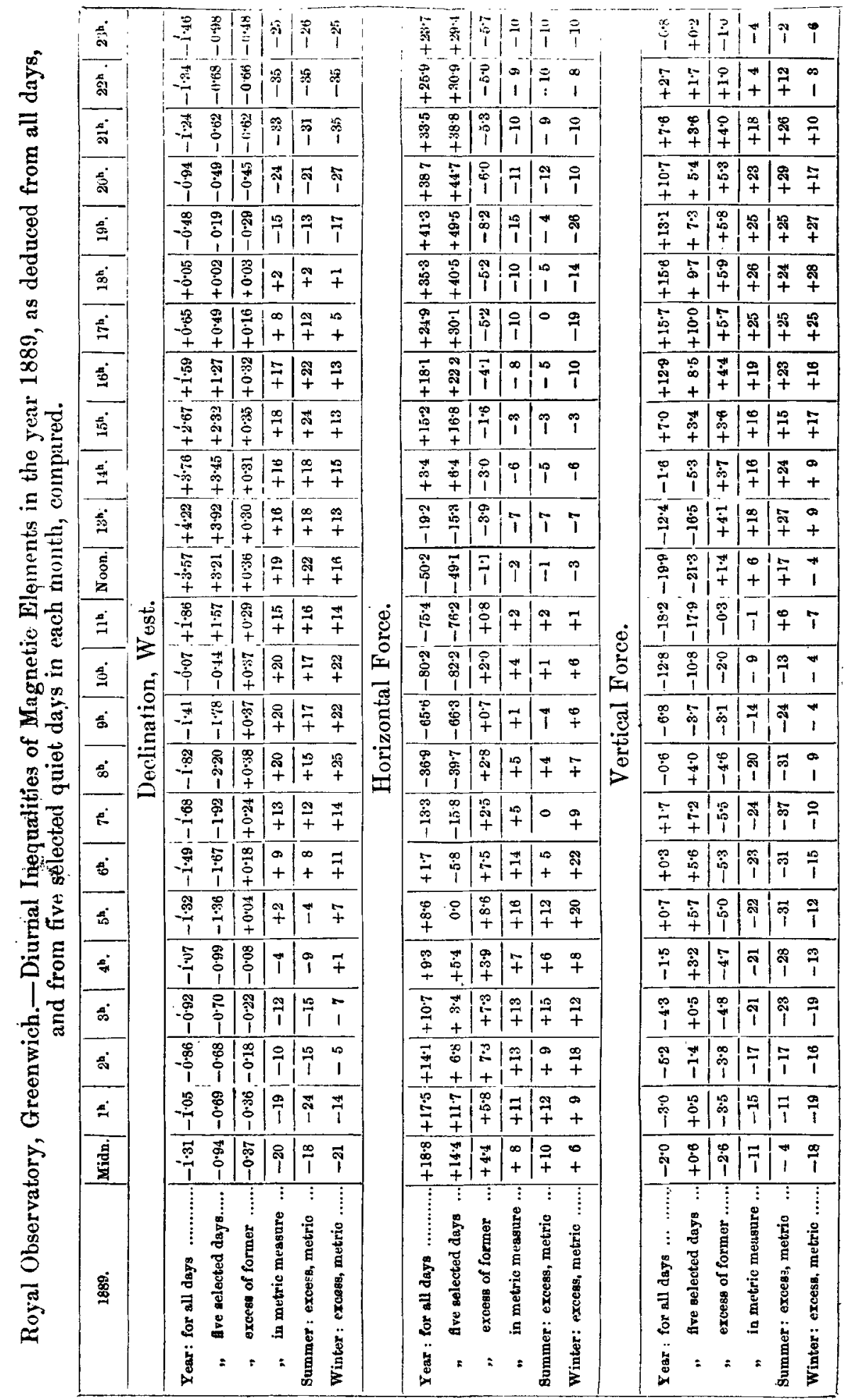


curves it will be seen occupy nearly similar positions, rise of the horizontal-force curve being accompanied by fall of the vertical-force curve; the nodal points for declination occupy an intermediate position. As regards the comparative magnitude of the deviations, the range (difference between the greatest and least) is, for declination $1^{\prime} \cdot 04\left(+0^{\prime} \cdot 38\right.$ to $\left.-0^{\prime} \cdot 66^{\prime}\right)$, or in metric measure $55(+20$ to -35$)$; for horizontal force, metric, $31(+16$ to -15$)$, and for vertical force $50(+26$ to -24). The sums of the twenty-four hourly deviations,

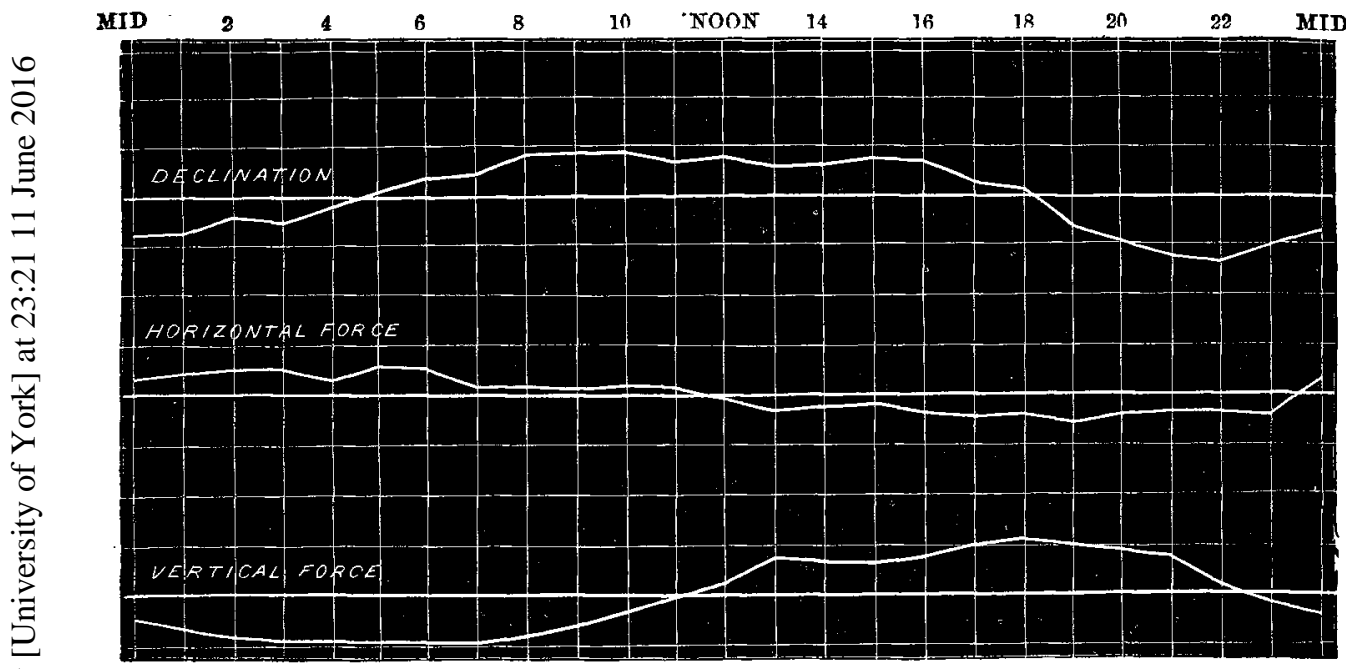

metric, taken without regard to sign, are for declination 392, for horizontal force 200 , and for vertical force 398 .

It is remarked by Messrs. Robson and Smith that the range of the diurnal inequality in declination in each of the three years 1883, 1886, and 1887 is less at Greenwich, including all days, than at Kew for quiet days, by $0^{\prime} \cdot 5,0^{\prime} \cdot 3$, and $0^{\prime} \cdot 5$ respectively, as though magnetic irregularities tended to diminish instead of increasing the diurnal range. In the following T'able there is given, in addition to the diurnal range (difference between greatest and least), the sums of the twenty-four hourly deviations from the mean, taken without regard to sign. 
Greenwich Magnetic Diurnal Inequalities, 1889.

\begin{tabular}{|c|c|c|c||c|c|c|}
\hline \multirow{2}{*}{ Flement. } & \multicolumn{3}{|c|}{ Range. } & \multicolumn{2}{|c|}{ Sums of 24 Deviations. } \\
\cline { 2 - 6 } & $\begin{array}{c}\text { All } \\
\text { days. }\end{array}$ & $\begin{array}{l}\text { Quiet } \\
\text { days. }\end{array}$ & $\begin{array}{c}\text { Excess } \\
\text { all days. }\end{array}$ & $\begin{array}{c}\text { All } \\
\text { days. }\end{array}$ & $\begin{array}{c}\text { Quiet } \\
\text { days. }\end{array}$ & $\begin{array}{c}\text { Excess } \\
\text { all days. }\end{array}$ \\
\hline Declination, in minutes ... & $6^{\prime} \cdot 04$ & $6^{\prime} \cdot 12$ & $-0^{\prime} \cdot 08$ & $36^{\prime} \cdot 83$ & $32^{\prime} \cdot 58$ & $+4^{\prime} \cdot 25$ \\
\hline Declination, metric ......... & 320 & 324 & -4 & 1952 & 1727 & +225 \\
Horizontal Force, metric... & 221 & 240 & -19 & 1240 & 1277 & -37 \\
Vertical Force, metric....... & 156 & 137 & +19 & 774 & 673 & +101 \\
\hline
\end{tabular}

Thus, comparing Greenwich values only, we find for 1889 mean of the three values of excess under Range $=-1$, and the mean under Sums of Deviations $=+96$. The latter is probably a better indication than the simple range of the influence of magnetic irregularities on the diurnal inequality formed from all days. But the discussion of the records of other years will throw further light on this point.

The question whether, in forming diurnal inequalities, all days should be employed, or selected days only, is one that has forced itself into notice in the discussion also of meteorological elements. For instance, in air-temperature, the ordinary diurnal change is in winter, at times, quite reversed, and the barometric movements are sometimes large and very irregular. But yet all days have been usually included in determining diurnal inequality. It may be questimable whether it is proper arbitrarily to reject days because they appear to be affected with irregularities which may themselves have a diurnal period. Indeed, considerable variation in amplitude of motion may be found to exist in magnetic registers on different quiet days in the same month. Considering, however, the amount of work involved in the tabulation of all days, the proposal to discuss the records of British magnetic observatories for five selected days monthly, in each year, will make a practical beginning in that which in magnetism is so much required-the tabulation of the records of different observatories on one uniform plan, in order to effect a more efficient and trustworthy comparison of results. 